\title{
CrystEngComm
}

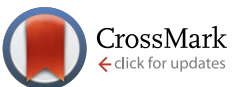

Cite this: CrystEngComm, 2016, 18 877

Received 6th November 2015, Accepted 4th January 2016

DOI: $10.1039 / c 5 c e 02171 e$

\section{Anion-induced self-assembly of positively charged polycyclic aromatic hydrocarbons towards nanostructures with controllable two-dimensional morphologies $\uparrow$}

\author{
Chongqing Yang, ${ }^{a}$ Dongqing Wu, ${ }^{\text {aa }}$ Wuxue Zhao, ${ }^{a}$ Weizhen $\mathrm{Ye}^{\mathrm{b}}{ }^{\mathrm{Z}}$ Zhixiao $\mathrm{Xu}{ }^{\mathrm{a}}$ \\ Fan Zhang ${ }^{a}$ and Xinliang Feng ${ }^{\text {ac }}$
}

www.rsc.org/crystengcomm

A controllable self-assembly strategy of positively charged polycyclic aromatic hydrocarbons (PCPAH) towards the formation of rectangle sheets and ribbon-like nanostructures has been achieved by choosing divalent anions with different sizes. In contrast, only rod-like nanostructures are obtained from PCPAH with univalent anions. It is revealed that the divalent anions play a key role in guiding the packing of $\mathrm{PCPAH}$, which provides an unprecedented route to fabricate two-dimensional nanostructures.

Over the last decade, the enthusiasm of scientific researchers towards two-dimensional (2D) nanomaterials has been boosted by graphene and its analogues due to their unique flat morphology and anisotropic chemical/physical behavior. ${ }^{1}$ However, the delicate fabrication of $2 \mathrm{D}$ materials with desired compositions and properties is still challenging. ${ }^{2}$ In this respect, the self-assembly of organic molecules provides a mild and solution processable strategy for the bottom-up fabrication of freestanding 2D soft nanomaterials. ${ }^{3}$ More importantly, the chemical and physical properties of these organic nanosheets, ${ }^{4}$ including electronic/photonic properties, ${ }^{5}$ porosity ${ }^{6}$ and metal or protein recognition activities ${ }^{7}$ can be precisely defined by the rational design of molecular building blocks.

Combining the extended aromatic frameworks with the incorporation of a charged heteroatom, PCPAH offer both strong $\pi-\pi$ interactions to enhance the molecular stacking and good affinity with polar solvents, making them attractive building blocks in supramolecular chemistry. ${ }^{8}$ Thus, one can tune the self-assembly behavior and optoelectronic properties of PCPAH via the modification of their aromatic core, substituents and associated anions, which render them highly

\footnotetext{
${ }^{a}$ School of Chemistry and Chemical Engineering, Shanghai JiaoTong University, 200240 Shanghai, China. E-mail: wudongqing@sjtu.edu.cn

${ }^{b}$ Research Institute of Petroleum Processing, SINOPEC, 100083 Beijing, China ${ }^{c}$ Department of Chemistry and Food Chemistry, Technische Universitaet Dresden, 01062 Dresden, Germany

$\dagger$ Electronic supplementary information (ESI) available: Materials, synthesis methods and additional characterization are presented. See DOI: 10.1039/ c5ce02171e
}

desirable candidates for the bottom-up synthesis of $2 \mathrm{D}$ soft nanomaterials. In our previous work, it was found that a typical PCPAH molecule, the 2-phenyl-9-benzo[8,9]quinolizino[4,5,6,7-fed]phenanthridinylium salt (PQP) containing a tetradecyl chain (shortened as $\mathrm{PQPC}_{14}$ ), can spontaneously self-organize into $2 \mathrm{D}$ ribbon-like nanostructures in solution with the short and rigid disulfonate anion serving as the cross-linker to direct the orientation of the neighbouring PQPC $_{14}$ cations. More importantly, the ribbon morphologies of the PQPs exhibited strong dependence on the rigidity and valences of the organic anions. ${ }^{9}$ Inspired by these results, we envision that the proper selection of inorganic divalent counteranions may also guide the packing behavior of PQPS with short alkyl chains and facilitate the formation of nanostructures with controlled 2D sheet-like morphologies.

Herein, the self-assembly behavior of hexyl-substituted PQPs $\left(\mathrm{PQPC}_{6}\right.$, Scheme 1) with divalent anions including tetrachloroplatinate $\left(\mathrm{PtCl}_{4}{ }^{2-}\right)$ and hexachloropalladate $\left(\mathrm{PdCl}_{6}{ }^{2-}\right)$ as well as univalent tetrachloroaurate $\left(\mathrm{AuCl}_{4}{ }^{-}\right)$in a binary solvent system (DMF/MeOH 1:7) was investigated. Interestingly, rectangle nanosheets were formed from $\mathrm{PQPC}_{6}$ salts employing $\mathrm{PtCl}_{4}{ }^{2-}$ as the counteranion. Moreover, the

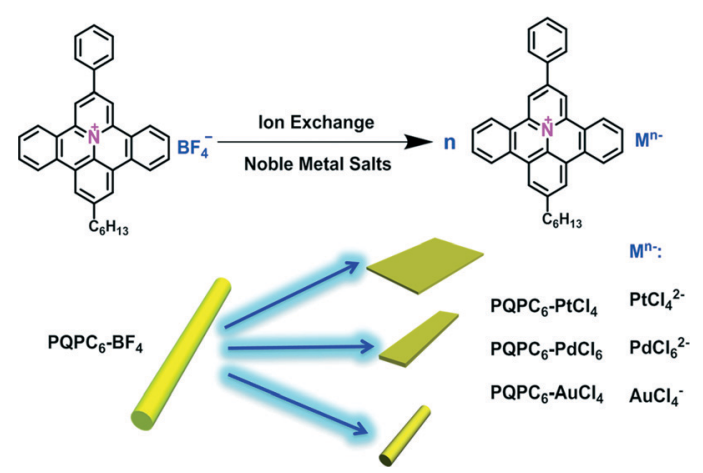

Scheme 1 The ion-exchange route for preparing $P Q P C_{6}$-based ionic complexes with different counter ions. 
control over the packing of $\mathrm{PQPC}_{6}$ cations could be further achieved by tuning the steric hindrance and valence of the counteranions with $\mathrm{PdCl}_{6}{ }^{2-}$ and $\mathrm{AuCl}_{4}{ }^{-}$, resulting in morphology variation from $2 \mathrm{D}$ ribbons to one-dimensional (1D) rods. Based on these results, it is revealed that the divalent anions $\left(\mathrm{PtCl}_{4}{ }^{2-}\right.$ and $\left.\mathrm{PdCl}_{6}{ }^{2-}\right)$ played a key role in adjusting the noncovalent interactions between the adjacent $\mathrm{PQPC}_{6}$ cations, thus giving rise to the unequal growth rates of the aggregates along different dimensions.

The ionic complexes of $\mathrm{PQPC}_{6}-\mathrm{M}\left(\mathrm{PQPC}_{6}-\mathrm{PtCl}_{4}, \mathrm{PQPC}_{6}-\right.$ $\mathrm{PdCl}_{6}$ and $\mathrm{PQPC}_{6}-\mathrm{AuCl}_{4}$, Scheme 1) were prepared from $\mathrm{PQPC}_{6}-\mathrm{BF}_{4}$ with potassium tetrachloroplatinate $\left(\mathrm{K}_{2} \mathrm{PtCl}_{4}\right)$, potassium hexachloropalladate $\left(\mathrm{K}_{2} \mathrm{PdCl}_{6}\right)$ and potassium tetrachloroaurate $\left(\mathrm{KAuCl}_{4}\right)$ in a one-to-one charge ratio via a facile ion-exchange procedure. ${ }^{10}$ Typically, $\mathrm{PQPC}_{6}-\mathrm{BF}_{4}$ was first dissolved in a binary solvent system (DMF/MeOH 1:7) and the aqueous solution containing the potassium salts of the corresponding anions was then added drop-wise (see the ESI $\dagger$ ). Due to the amphiphilic nature of the ionic complex, aggregates with an ordered packing in such a mixed solvent were obtained as direct precipitate from the solution. The compositions of the obtained three ionic complex aggregates were confirmed by the elemental analysis results (Table S1 $\uparrow$ ) and Fourier transform infrared (FTIR) spectra (Fig. S1 $\dagger$ ).

The morphology of the aggregates from $\mathrm{PQPC}_{6}-\mathrm{PtCl}_{4}$ was first investigated by scanning electron microscopy (SEM) and transmission electron microscopy (TEM). As shown in Fig. 1a and b, rectangle-shaped 2D nanosheets with sharp edges were obtained. The width of the nanosheets is between 200 and $400 \mathrm{~nm}$, while the length is in the range of 200 nm-1 $\mu \mathrm{m}$. The atomic force microscopy (AFM) image (Fig. 1c) reveals that the nanosheets of $\mathrm{PQPC}_{6}-\mathrm{PtCl}_{4}$ have a smooth surface with a height of $\sim 23 \mathrm{~nm}$, further confirming their $2 \mathrm{D}$ morphology. It should be noted that the mixed solvent in this work is essential for the formation of the above mentioned $2 \mathrm{D}$ aggregates and that the aggregates do not form when either DMF or $\mathrm{MeOH}$ alone was used as the solvent (Fig. S2 $\dagger$ ).

The wide-angle X-ray diffraction (WAXD) patterns of $\mathrm{PQPC}_{6}-\mathrm{PtCl}_{4}$ show intense peaks at 4.2, 7.6, 8.5 and 9.7० (Fig. 2a), corresponding to the (100), (101), (200) and (010) facets of a monoclinic packing, respectively. The diffraction peak at approximately $25.2^{\circ}$ is attributed to the $\pi-\pi$ stacking

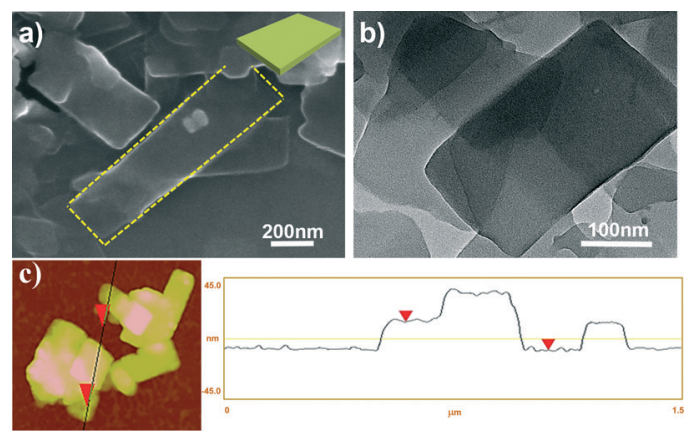

Fig. 1 (a) SEM and (b) TEM images; (c) AFM image and height profile of rectangular nanosheets formed by ionic complex $\mathrm{PQPC}_{6}-\mathrm{PtCl}_{4}$. a)

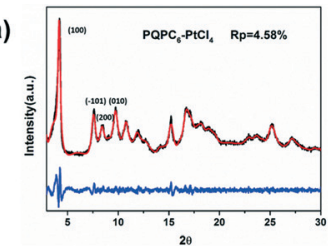

b)

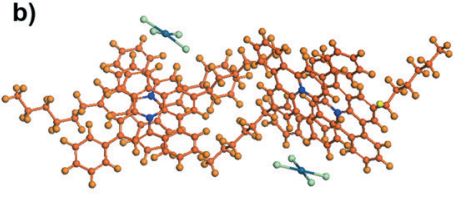

c)

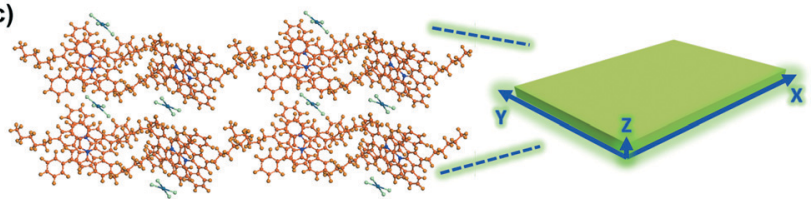

Fig. 2 (a) The experimental WAXD pattern (black), the Pawley refined one (red) and a difference plot (blue) of $\mathrm{PQPC}_{6}-\mathrm{PtCl}_{4}$; (b) the possible packing model of $\mathrm{PQPC}_{6}-\mathrm{PtCl}_{4}$ with a slipped head-to-head arrangement; (c) the theoretical 2D staggered structure of the $\mathrm{PQPC}_{6}-\mathrm{PtCl}_{4}$ aggregates (orange: $\mathrm{C}$; blue: $\mathrm{N}$; green: $\mathrm{Cl}$; dark green: $\mathrm{Pt}$ ) and the schematic illustration of the 2D nanostructures from $\mathrm{PQPC}_{6}-\mathrm{PtCl}_{4}$

of the aromatic frameworks of $\mathrm{PQPC}_{6}$ cations. ${ }^{9}$ Based on these results, Pawley refinement on the Reflux Plus module of the Materials Studio program version 6.1 was subsequently executed to calculate the unit cell parameters of $\mathrm{PQPC}_{6}-\mathrm{PtCl}_{4}$ in the rectangular nanosheets. ${ }^{11}$ With the profile-fitting factors $\mathrm{w} R_{\mathrm{p}}$ and $R_{\mathrm{p}}$ being 6.35 and $4.58 \%$ respectively, the unit cell parameters of $\mathrm{PQPC}_{6}-\mathrm{PtCl}_{4}$ are calculated to be $a=23.10$ $\AA$ А $b=9.08 \AA$, and $c=11.70 \AA$ (Table S2 $\dagger$ ).

Accordingly, the packing behavior of $\mathrm{PQPC}_{6}-\mathrm{PtCl}_{4}$ in the rectangular nanosheets could be proposed by considering the previously reported packing mode of PQPs with different counteranions. ${ }^{8 b, 9}$ As illustrated in Fig. 2b, two neighbouring $\mathrm{PQPC}_{6}$ cations can form a dimer structure in the aggregates with their aromatic core arranged in a slipped head-to-head manner and the $\mathrm{PtCl}_{4}{ }^{2-}$ anion shared by two cations located at their bay position. Driven by the local micro-phase separation between their soft and rigid parts, these dimers can further stack together via non-covalent forces including $\pi-\pi$ interactions, ionic interactions, etc. ${ }^{8 c}$

The simulated packing model from a quantum chemical calculation on CASTEP (Cambridge Sequential Total Energy Package) suggests that the stacking of the molecules along the three dimensions is mainly dominated by three kinds of non-covalent forces: solvophobic interactions along the $X$-axis, electrostatic effects between the $\mathrm{PQPC}_{6}{ }^{+}-\mathrm{PtCl}_{4}{ }^{2-}$ ion pairs along the $Y$-axis, and the $\pi-\pi$ interactions along the $Z$-axis (Fig. 2c). Under polar experimental conditions, the solvophobic interactions between the alkyl moieties will be enhanced along the $X$-axis, and the strong electrostatic interactions between the cation-anion pairs greatly inhibit the repulsion between the adjacent dimers along the $Y$-axis. ${ }^{12}$ However, the centrally charged aromatic core would prefer to expose themselves to the solvent, thus causing a slipped faceto-face structure between the adjacent cations and greatly reducing $\pi-\pi$ interactions along the $Z$-axis. Driven by these interactions, the packing of the PCPAH in the direction parallel to the $X-Y$ interfaces should be much faster than that in 
the direction along the $Z$-axes, hence leading to the formation of $2 \mathrm{D}$ nanostructures.

The formation of $2 \mathrm{D}$ nanostructures from $\mathrm{PQPC}_{6}-\mathrm{PtCl}_{4}$ inspired us to further study the self-assembly behavior of $\mathrm{PQPC}_{6}-\mathrm{PdCl}_{6}$, which also contains a divalent complex anion with a larger volume (ionic radius $\mathrm{PtCl}_{4}{ }^{2-}=3.07 \AA, \mathrm{PdCl}_{6}{ }^{2-}=$ $3.33 \AA$ A). ${ }^{13}$ As demonstrated in the SEM and TEM images, the aggregates of $\mathrm{PQPC}_{6}-\mathrm{PdCl}_{6}$ are uniform nanoribbons with a length of $600 \mathrm{~nm}$ to several micrometres and a width of 100 to $300 \mathrm{~nm}$ (Fig. 3a and b). AFM characterization shows that the thickness of the nanoribbons is around $47 \mathrm{~nm}$ (Fig. 3c).

Different from $\mathrm{PQPC}_{6}-\mathrm{PtCl}_{4}$, the WAXD patterns of $\mathrm{PQPC}_{6}-\mathrm{PdCl}_{6}$ exhibit obvious diffractions at 6.06, 9.00, 10.80 and $12.12^{\circ}$, which are typical for the (001), (010), (101) and (002) facets of a triclinic packing. Additionally, the diffraction at $25.4^{\circ}$ is attributed to the $\pi-\pi$ interactions among the aromatic frameworks of $\mathrm{PQPC}_{6}$ cations. The lattice parameters of the triclinic space group formed by $\mathrm{PQPC}_{6}-\mathrm{PdCl}_{6}$ are calculated as $a=8.40 \AA, b=14.93 \AA$ and $c=21.39 \AA$ with the $\mathrm{w} R_{\mathrm{p}}$ and $R_{\mathrm{p}}$ converged to 12.80 and $9.26 \%$, separately (Fig. $4 \mathrm{a}$ ).

According to the XRD patterns, the structural simulation suggests that the aggregates of $\mathrm{PQPC}_{6}-\mathrm{PdCl}_{6}$ have a similar packing model to that of $\mathrm{PQPC}_{6}-\mathrm{PtCl}_{4}$ with their anions embedded between the solvophilic interfaces (Fig. 4b). However, since the ionic radius of $\mathrm{PdCl}_{6}{ }^{2-}$ is larger than that of $\mathrm{PtCl}_{4}{ }^{2-}$, the steric hindrance caused by the anions will push them away from the $\mathrm{PQPC}_{6}{ }^{+}$cations. As a result, the packing of $\mathrm{PQPC}_{6}-\mathrm{PdCl}_{6}$ along the $Y$-axis is restricted since there is not enough space for the accommodation of $\mathrm{PdCl}_{6}{ }^{2-}$ to balance the increased positive charge density along the $Y$-axis. Thus, the width of the aggregates is shorter than that of the nanosheets from $\mathrm{PQPC}_{6}-\mathrm{PtCl}_{4}$, resulting in the ribbon-like morphology. Although different anions can cause varied morphologies, our experimental results indicate that the combination of $\mathrm{PtCl}_{4}{ }^{2-}$ and $\mathrm{PdCl}_{6}{ }^{2-}$ won't lead to the formation of aggregates with a new morphology and only the mixture of nanosheets and nanoribbons can be obtained (Fig. S3†).

We further explored the impact of the counteranions with different charges on the PQP-based ionic complexes; the selfassembly behavior of $\mathrm{PQPC}_{6}-\mathrm{AuCl}_{4}$ was thus investigated in this work. Interestingly, only rod-like aggregates with a length

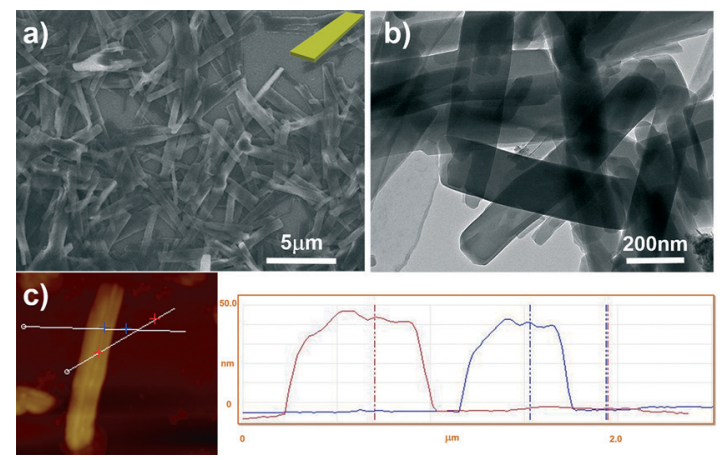

Fig. 3 (a) SEM and (b) TEM images; (c) AFM image with a height profile from the $2 \mathrm{D}$ nanoribbons formed by $\mathrm{PQPC}_{6}-\mathrm{PdCl}_{6}$. a)
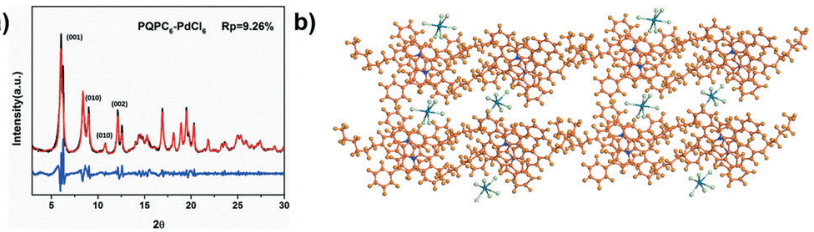

Fig. 4 (a) The experimental WAXS pattern (black), the Pawley refined one (red) and a difference plot (blue) of $\mathrm{PQPC}_{6}-\mathrm{PdCl}_{6} ;$ (b) the theoretical possible $2 \mathrm{D}$ staggered structure of the $\mathrm{PQPC}_{6}-\mathrm{PdCl}_{6}$ aggregates (orange: $\mathrm{C}$; blue: $\mathrm{N}$; green: $\mathrm{Cl}$; dark green: $\mathrm{Pd}$ ).

in the range from $600 \mathrm{~nm}$ to $1 \mu \mathrm{m}$ and a diameter ranging from 60 to $100 \mathrm{~nm}$ were obtained (Fig. 5a and b). AFM characterization (Fig. 5c) reveals a thickness of $\sim 67 \mathrm{~nm}$. Different from $\mathrm{PQPC}_{6}-\mathrm{PtCl}_{4}$ and $\mathrm{PQPC}_{6}-\mathrm{PdCl}_{6}$, the WAXD patterns of $\mathrm{PQPC}_{6}-\mathrm{AuCl}_{4}$ contain four sharp diffraction peaks at 6.32 , $8.36,9.60$, and $12.74^{\circ}$, corresponding to the (001), (010), (100), (002) facets of the triclinic structure. The simulation profile of $\mathrm{PQPC}_{6}-\mathrm{AuCl}_{4}$ (Fig. 5d) also fits well with the experimental data with $\mathrm{w} R_{\mathrm{p}}$ and $R_{\mathrm{p}}$ converged to 11.74 and $8.63 \%$ and the parameters of the unit cell for $\mathrm{PQPC}_{6}-\mathrm{AuCl}_{4}$ are determined to be $a=10.63 \AA, b=10.67 \AA$, and $c=16.00 \AA$.

According to the above calculation, the simulated packing model of $\mathrm{PQPC}_{6}-\mathrm{AuCl}_{4}$ is shown in Fig. 5e. Compared with $\mathrm{PQPC}_{6}-\mathrm{PtCl}_{4}$, the electrostatic repulsion between the adjacent dimers of $\mathrm{PQPC}_{6}-\mathrm{AuCl}_{4}$ along the $Y$-axis would increase significantly since $\mathrm{AuCl}_{4}{ }^{-}$is a monovalent anion, which would remarkably restrict the growth rate along the $Y$-axis. Thus, the $1 \mathrm{D}$ rod-like aggregates are derived from $\mathrm{PQPC}_{6}-\mathrm{AuCl}_{4}$.

In conclusion, we have demonstrated the synthesis and self-assembly of three hexyl-substituted PQP salts with different inorganic anions. By using counter-anions with different
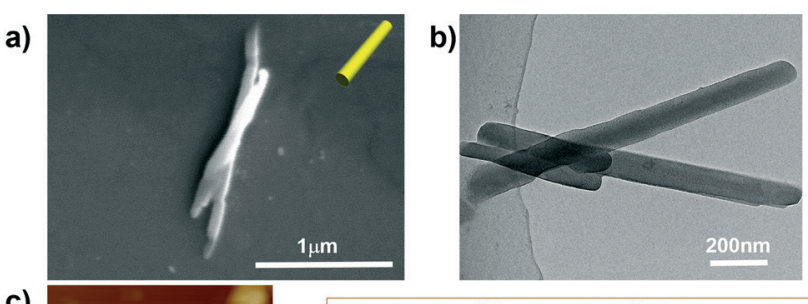

c)
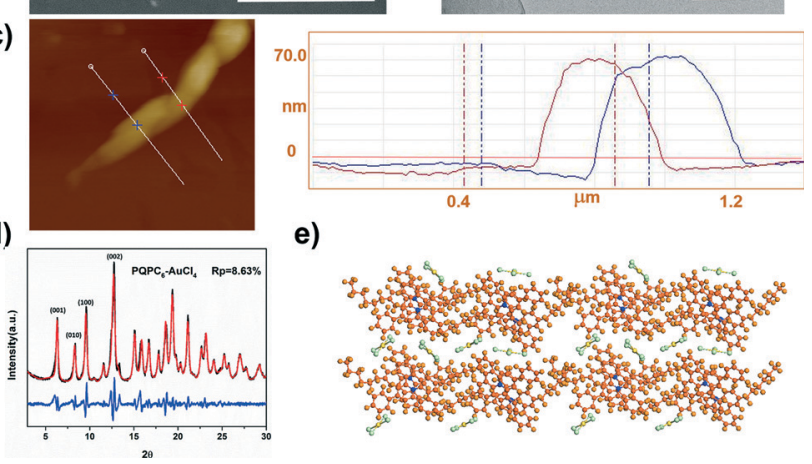

Fig. 5 (a) SEM and (b)TEM images; (c)AFM images of 1D rod formed by ionic complex $\mathrm{PQPC}_{6}-\mathrm{AuCl}_{4}$; (d) the experimental WAXS pattern (black) and the Pawley refined one (red) of $\mathrm{PQPC}_{6}-\mathrm{AuCl}_{4}$; (e) the theoretical possible 2D staggered structure of the $\mathrm{PQPC}_{6}-\mathrm{AuCl}_{4}$ aggregates (blue: $\mathrm{C}$; orange: $\mathrm{N}$; green: $\mathrm{Cl}$; dark green: $\mathrm{Au}$ ). 
sizes and valances, the packing of $\mathrm{PQPC}_{6}$ cations along different dimensions could be easily tuneable, giving rise to different morphologies from $2 \mathrm{D}$ nanosheets to $1 \mathrm{D}$ nanorods. In line with these arguments, it could be concluded that the divalent inorganic anions $\left(\mathrm{PtCl}_{4}{ }^{2-}\right.$ and $\left.\mathrm{PdCl}_{6}{ }^{2-}\right)$ in the $\mathrm{PQPC}_{6}{ }^{-}$ based ionic complexes can effectively adjust the non-covalent interactions between the adjacent $\mathrm{PQPC}_{6}$ cations and direct the packing of the $\mathrm{PQPC}_{6}$ salts into $2 \mathrm{D}$ aggregates. Thus, it is anticipated that this approach can be applied to restructure the order and arrangement of the functional organic molecules in their aggregates, which will provide new opportunities for the fabrication of miniaturized optoelectronic devices.

\section{Acknowledgements}

This work was financially supported by the 973 Program of China (2014CB239701, 2013CBA01602 and 2012CB933404), Natural Science Foundation of China (21320102006, 61235007, 61575121, 21572132 and 21372155), Professor of Special Appointment at Shanghai Institutions of Higher Learning, Science and Technology Commission of Shanghai Municipal (12JC1404900), MPI-SJTU Partner Group Project (M.CH.A.Poly0004), ERC project on 2DMATER and EU Graphene Flagship. We also thank the Instrumental Analysis Center of Shanghai Jiao Tong University for the characterization of the materials.

\section{Notes and references}

1 (a) X. Huang, C. Tan, Z. Yin and H. Zhang, Adv. Mater., 2014, 26, 2185; (b) R. Mas-Balleste, C. Gomez-Navarro, J. Gomez-Herrero and F. Zamora, Nanoscale, 2011, 3, 20; (c) C. N. R. Rao, H. S. S. Ramakrishna Matte and U. Maitra, Angew. Chem., Int. Ed., 2013, 52, 13162; (d) J. Sakamoto, J. van Heijst, O. Lukin and A. D. Schluter, Angew. Chem., Int. Ed., 2009, 48, 1030.
2 (a) M. Chhowalla, H. S. Shin, G. Eda, L.-J. Li, K. P. Loh and H. Zhang, Nat. Chem., 2013, 5, 263; (b) T. Govindaraju and M. B. Avinash, Nanoscale, 2012, 4, 6102.

3 X. Zhuang, Y. Mai, D. Wu, F. Zhang and X. Feng, Adv. Mater., 2015, 27, 403.

4 (a) T. Bauer, Z. Zheng, A. Renn, R. Enning, A. Stemmer, J. Sakamoto and A. D. Schlüter, Angew. Chem., 2011, 123, 8025; (b) Y. Zheng, H. Zhou, D. Liu, G. Floudas, M. Wagner, K. Koynov, M. Mezger, H.-J. Butt and T. Ikeda, Angew. Chem., 2013, 125, 4945.

5 W. Yao, Y. Yan, L. Xue, C. Zhang, G. Li, Q. Zheng, Y. S. Zhao, H. Jiang and J. Yao, Angew. Chem., 2013, 125, 8875.

6 G. Das, B. P. Biswal, S. Kandambeth, V. Venkatesh, G. Kaur, M. Addicoat, T. Heine, S. Verma and R. Banerjee, Chem. Sci., 2015, 6, 3931.

7 E. J. Robertson, G. K. Olivier, M. Qian, C. Proulx, R. N. Zuckermann and G. L. Richmond, Proc. Natl. Acad. Sci. U. S. A., 2015, 112, 338.

8 (a) D. Wu, X. Feng, M. Takase, M. C. Haberecht and K. Müllen, Tetrahedron, 2008, 64, 11379; (b) D. Wu, W. Pisula, V. Enkelmann, X. Feng and K. Müllen, J. Am. Chem. Soc., 2009, 131, 9620; (c) D. Wu, W. Pisula, M. C. Haberecht, X. Feng and K. Müllen, Org. Lett., 2009, 11, 5686; (d) D. Wu, L. Zhi, G. J. Bodwell, G. Cui, N. Tsao and K. Müllen, Angew. Chem., Int. Ed., 2007, 46, 5417.

9 D. Wu, R. Liu, W. Pisula, X. Feng and K. Müllen, Angew. Chem., Int. Ed., 2011, 50, 2791.

10 J. Zhang, Y. Yan, M. W. Chance, J. Chen, J. Hayat, S. Ma and C. Tang, Angew. Chem., 2013, 125, 13629.

11 E. L. Spitler and W. R. Dichtel, Nat. Chem., 2010, 2, 672.

12 S. Ghosh, A. Roy, D. Banik, N. Kundu, J. Kuchlyan, A. Dhir and N. Sarkar, Langmuir, 2015, 31, 2.

13 W. M. Haynes, T. J. Bruno and D. R. Lide, CRC Handbook of Chemistry and Physics, Internet Version, 85th edn, 2004. 